\title{
Currently available treatment options for neuroendocrine liver metastases
}

\author{
Nikolaos Machairas ${ }^{a *}, K^{\prime}$ osmas Daskalakis ${ }^{\mathrm{b} *}$, Evangelos Felekourasc, Krystallenia I. Alexandraki ${ }^{\mathrm{b}}$, \\ Gregory Kaltsas ${ }^{b}$, Georgios C. Sotiropoulos ${ }^{a}$
}

National and Kapodistrian University of Athens, Medical School, Athens, Greece

\begin{abstract}
Neuroendocrine neoplasms (NEN) are frequently characterized by a high propensity for metastasis to the liver, which appears to be a dominant site of distant-stage disease, affecting quality of life and overall survival. Liver surgery with the intention to cure is the treatment of choice for resectable neuroendocrine liver metastases (NELM), aiming to potentially prolong survival and ameliorate hormonal symptoms refractory to medical control. Surgical resection is indicated for patients with NELM from well-differentiated NEN, while its feasibility and complexity are largely dictated by the degree of liver involvement. As a result of advances in surgical techniques over the past decades, complex 1- and 2-stage, or repeat liver resections are performed safely and effectively by experienced surgeons. Furthermore, liver transplantation for the treatment of NELM should be anchored in a multimodal and multidisciplinary therapeutic strategy and restricted only to highly selected individual cases. A broad spectrum of interventional radiology treatments for NELM have recently been available, with expanding indications that are more applicable, as they are less limited by patient- and tumor-related parameters, being therefore important adjuncts or alternatives to surgery. Overall, liver-targeted treatment modalities may precede the administration of systemic molecular targeted agents and chemotherapy for patients with liver-dominant metastatic disease; these appear to be a crucial component of multimodal management of patients with NEN. In the present review, we discuss surgical and non-surgical liver-targeted treatment approaches for NELM, each complementing the other, with a view to assisting physicians in optimizing multimodal NEN patient care.
\end{abstract}

Keywords Neuroendocrine, liver metastasis, surgery, ablation, embolization

Ann Gastroenterol 2021; 34 (2): 1-16

\section{Introduction}

Neuroendocrine neoplasms (NEN) represent a group of heterogeneous tumors that most frequently (70-75\%) involve the gastro-entero-pancreatic (GEP) organs [1]. The majority of

a2nd Department of Propaedeutic Surgery (Nikolaos Machairas, Georgios C. Sotiropoulos); ${ }^{b} 1$ st Department of Propaedeutic Internal Medicine (Kosmas Daskalakis, Krystallenia I. Alexandraki, Gregory Kaltsas); ' 1 st Department of Surgery (Evangelos Felekouras), National and Kapodistrian University of Athens, Medical School, Athens, Greece

*These authors contributed equally

Conflict of Interest: None

Correspondence to: Georgios C. Sotiropoulos, MD, PhD, FEBS, FACS, 2nd Department of Propaedeutic Surgery, University of Athens Medical School, General Hospital Laiko, 17 Agiou Thoma St., 11527 Athens,

Greece, e-mail geosotirop@med.uoa.gr

Received 23 July 2020; accepted 10 September 2020; published online 16 January 2021

DOI: https://doi.org/10.20524/aog.2021.0574
NENs are well differentiated (WD-NENs) and their biological behavior is determined by their proliferation capacity (grading $\mathrm{G})$, based on the Ki67 proliferation index (Ki67 \% LI). Grade 1 (G1 Ki67 LI $\leq 2 \%)$, and G2 (3-20\%) neuroendocrine tumors (NETs) generally show less aggressive behavior, exhibiting prolonged survival even in the context of metastatic disease; a subset of WD-NENs have Ki67 LI >20\% (G3NETs) [2]. Poorly differentiated GEP-NENs are designated as neuroendocrine carcinomas (NEC) and exhibit aggressive behavior leading to a poor outcome. Most NENs are non-functioning, while approximately $20-30 \%$ present with symptoms related to the secretion of bioactive compounds (peptides, amines) leading to distinct clinical syndromes [3].

Surgical resection represents the ideal therapeutic modality for tumor eradication and a potential "cure" for NENs. However, as most of these neoplasms present late with disseminated disease, resulting from asymptomatic presentation and/or the presence of non-specific symptoms, radical surgery is commonly reserved only for a small proportion of patients [1,2]. Even so, survival for all NENs has improved over time, including metastatic GEP-NENs, possibly reflecting improvements in classification systems and therapies applied [4]. 
A significant proportion of patients with NENs will commonly be diagnosed with synchronous neuroendocrine liver metastases (NELM), or will develop them metachronously during the course of their disease [5,6]. The exact incidence of NELM remains poorly determined and is reported to range from $27-90 \%[2,7,8]$. This can be partly attributed to hepatic lesions being erroneously reported as distant metastases, rather than NELM specifically, and also to referral biases [6]. Approximately $50 \%$ of patients with pancreatic NENs (panNEN) and 60$75 \%$ of patients with small intestinal NENs (SI-NENs) either present with synchronous NELM or develop metachronous NELM [8-10]. In contrast, patients with gastric, appendiceal and rectal NEN primaries are less likely to develop NELM, whereas $5-10 \%$ of patients will be diagnosed with NELM of unknown primary $[6,11]$. The presence of NELM is a major predictor of adverse long-term outcomes [5,12], while available treatment options vary, depending on the extent of hepatic involvement and patients' performance status. A number of liver tumor burden classification systems have been developed; one of the most commonly used was proposed by Frilling et al (Fig. 1) [13].

Following accurate identification of the extent of metastatic disease, thorough discussion in the context of a multidisciplinary board is paramount and is expected to outline the available and most suitable treatment options, as with other malignant conditions [14,15]. These tailored-to-the-patient treatment options can be applied sequentially or combined, highlighting the critical need for coordination between all subspecialties involved. As previously mentioned, patients with NELM frequently present with an extensive tumor load, whilst treating the patient in a manner that acknowledges the often relatively indolent nature of NEN progression should be the goal of treatment [16]. The selection of treatment options is adjusted accordingly, based on patient performance status, associated comorbidities, meticulous tumor staging, and assessment of prognostic factors [17].

Although liver surgery is the only therapeutic approach with curative intent, it is not unequivocally clear whether it prolongs overall survival (OS) in patients with NELM, as conflicting reports have been published and no randomized studies have been performed [18-23]. Nevertheless, complete hepatic resection (R0) is only feasible in approximately $10-25 \%$ of all NELM patients, as many exhibit bilobar liver involvement [2,13], whereas a significant proportion of NELM may elude detection on preoperative imaging [24,25]. Furthermore, surgical resection with curative intent is not indicated in patients with poorly differentiated tumors, extensive disease, existing comorbidities and/or frailty making surgery unsafe [2].

The application of local, non-surgical liver-targeted treatment modalities (local ablation, transarterial hepatic embolization [TAE] or chemo-embolization [TACE], radioembolization [RE] and peptide receptor radionuclide therapy [PRRT]) is largely dependent on local expertise, and on the extent and location of hepatic involvement [2].

These treatment options are frequently considered in the context of multimodal management for WD-NENs with progressive, unresectable NELM and/or hormonal syndromes refractory to conventional medical treatment. If hepatic resection and/or minimally invasive techniques targeting NELM are not feasible, or in cases of extrahepatic metastatic spread, systemic treatment is then clinically indicated (Fig. 2).

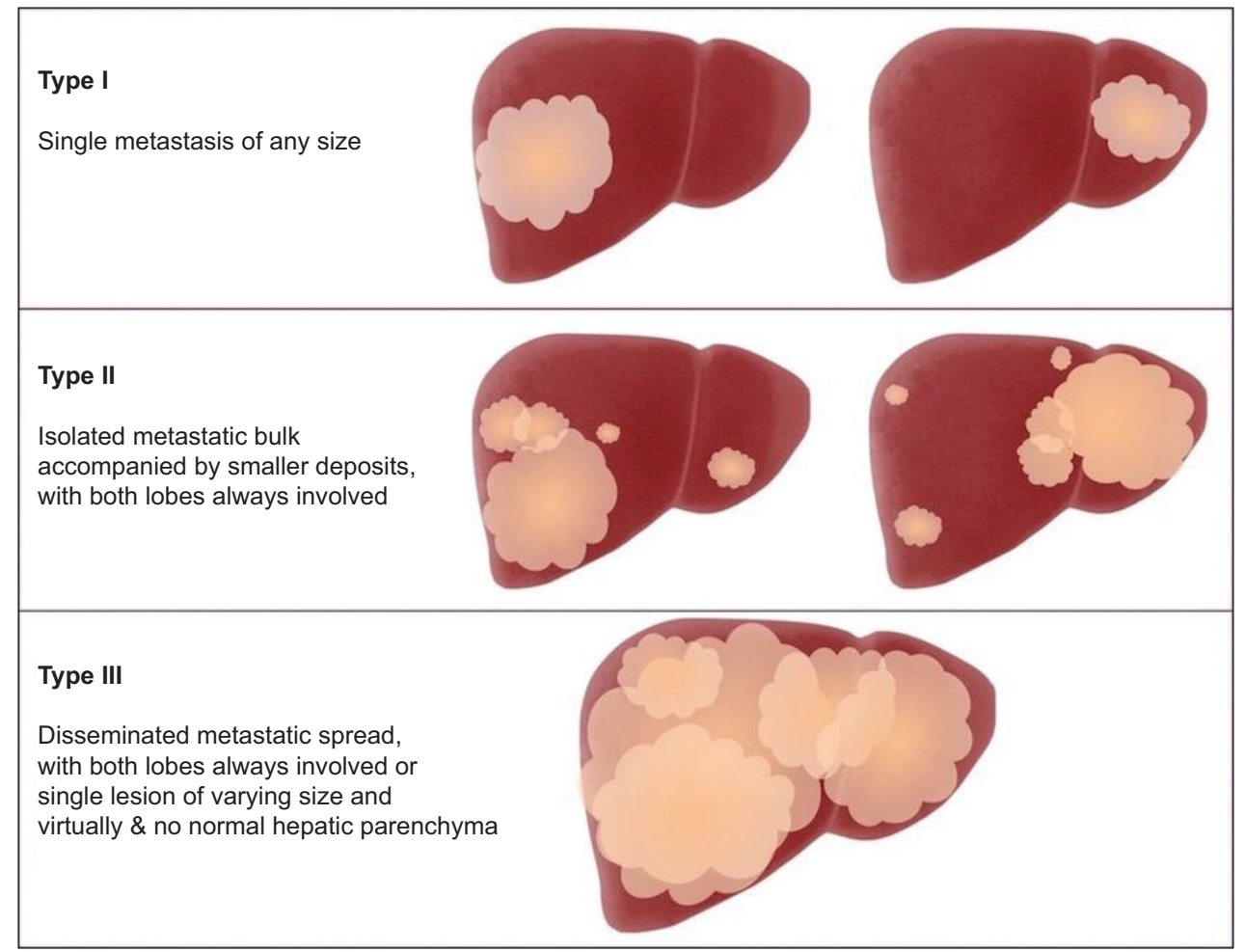

Figure 1 Proposed types of neuroendocrine liver metastases distribution [13] 
In cases of bulky disease, locoregional options may also be indicated in the early stages for down-staging. Notably, systemic therapies for NENs act on all metastatic sites and are not liver-specific [3].

The present review aims to address the currently available treatment options targeting patients with NELM mainly of GEP origin, elucidating the role of liver surgery and that of minimally-invasive liver-targeted therapeutic modalities, in the context of multidisciplinary team management.

\section{Surgical treatment options}

\section{Isolated surgical resection}

Patients with WD-NENs and resectable NELM with an adequate future liver remnant (FLR) of at least 30\% are considered eligible for curative-intent resection [10]. Although multiple studies over the past decades have demonstrated that patients who undergo complete resection of NELM have better outcomes, opinions are divided as to whether these favorable outcomes illustrate the true therapeutic effect of the approach, or are rather the result of selection and immortal time biases (Table 1) [8,26-35].

A first large systematic review of 29 studies aimed to evaluate the safety and efficacy of hepatectomy for patients with NELMs, as well as to identify prognostic factors for survival [26]. The authors showed that liver resections for these patients were safe, with a median overall perioperative mortality of $0 \%$ and a median morbidity rate of $23 \%$. Microscopically confirmed complete (R0) resection was achieved in $63 \%$ of patients (range $38-100 \%$ ). The reported median 5-year OS rates for patients undergoing isolated liver resections and a combination of resection and ablation were $70 \%$ and $71.5 \%$, respectively. Notably, a $95 \%$ median rate of symptom relief was also found. Lastly, with regard to prognostic variables, poor differentiation and extrahepatic

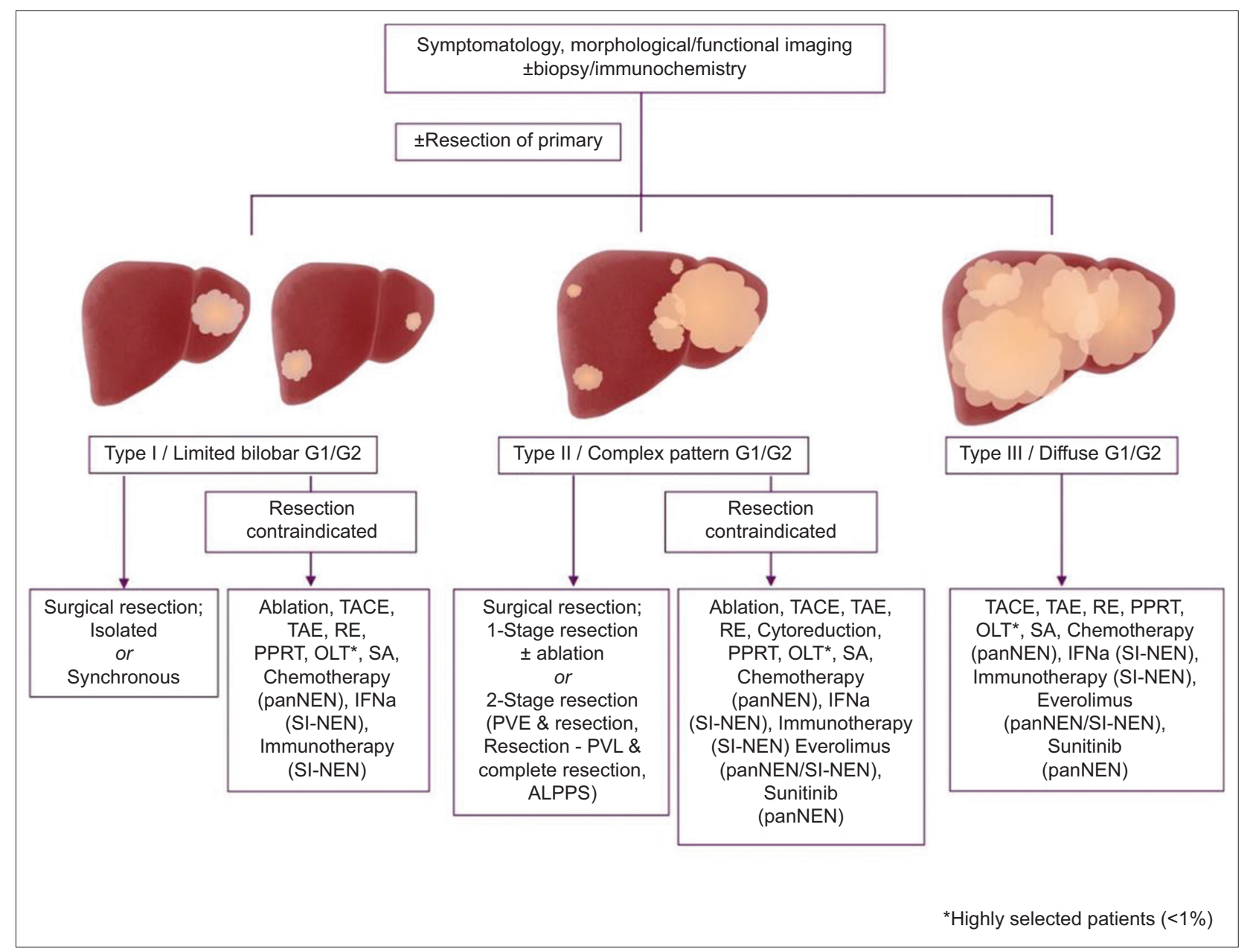

Figure 2 Treatment algorithm for well-differentiated (G1/G2) neuroendocrine liver metastases

TACE, transarterial chemoembolization; TAE, transarterial embolization; RE, radio-embolization; PPRT, peptide receptor radionuclide therapy, OLT, orthotopic liver transplantation; SA, somatostatin analogues; panNEN, pancreatic neuroendocrine neoplasm; IFNa, interferon alpha; SI-NEN, small intestine neuroendocrine neoplasm; $P V E$, portal vein embolization; $P V L$, portal vein ligation; ALPPS, associating liver partition and portal vein ligation for staged hepatectomy 


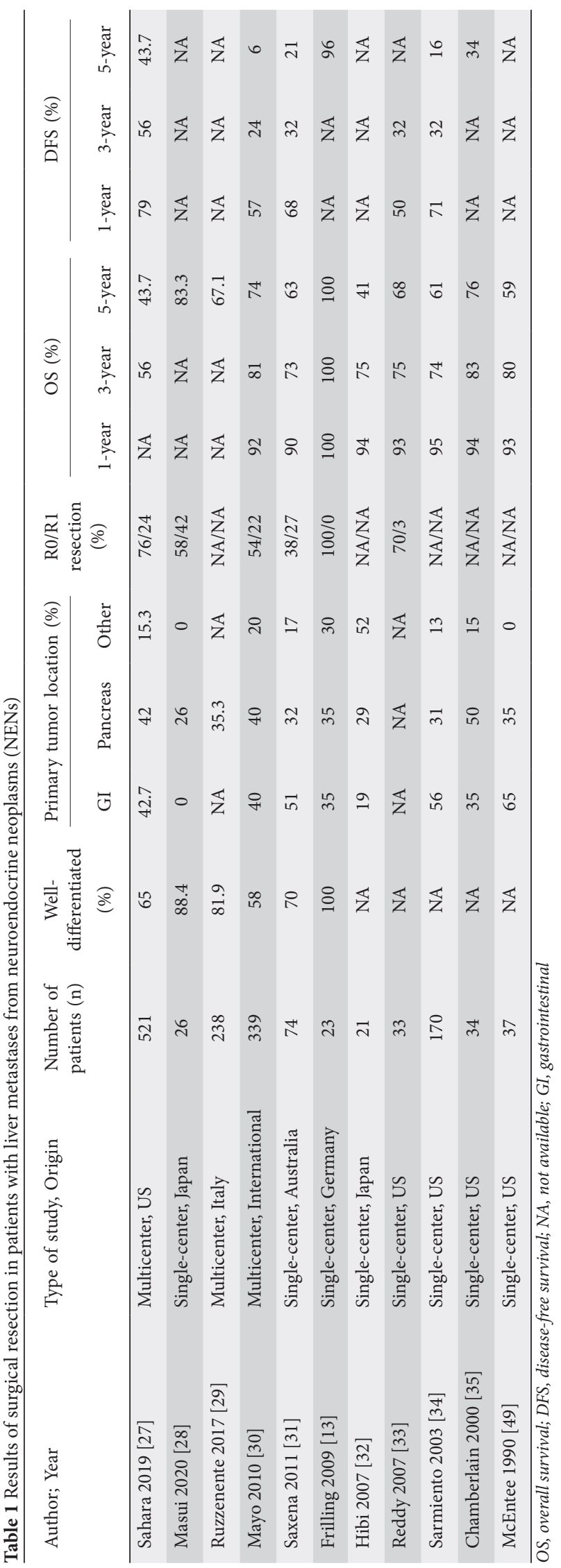

extent of disease were confirmed as independent negative prognostic factors for OS [26].

A recent meta-analysis of 1108 patients with NELM from GEP-NENs confirmed favorable survival outcomes by liver surgery compared to chemotherapy (odds ratio [OR] 0.05, 95\% confidence interval $[\mathrm{CI}]$ 0.01-0.21; $\mathrm{P}<0.0001)$, embolization (OR 0.18, 95\%CI 0.05-0.61; $\mathrm{P}=0.006$ ), and no NELM resection (OR 0.15, 95\%CI 0.05-0.42; $\mathrm{P}=0.0003$ ) [36]. These findings were in agreement with a previous systematic review and meta-analysis, which evaluated survival outcomes of patients with NELM from panNENs alone [37]. In that study, patients who underwent liver surgery for NELM had median 1-, 3- and 5-year OS rates of $92.69 \%, 76.93 \%$ and $67.54 \%$, respectively, all superior to the equivalent $O S$ rates of the non-resection groups $(77.31 \%, 40.94 \%$, and $26.6 \%$, respectively; all $\mathrm{P}<0.001)$. The authors also showed that, regardless of the functional or non-functional nature of the primary panNET, patients who underwent resection had a higher chance of experiencing associated symptom relief, including hormonal and mechanical symptoms (OR 2.49, 95\%CI 1.03-6.04; $\mathrm{P}=0.04$ ). It should be taken into account, though, that all these outcomes are derived from partly heterogeneous, retrospective, non-randomized trials and thus their outcomes are subject to multiple biases.

\section{Staged resections for extensive disease}

As a result of advances in surgical techniques, staged resections of complex and extensive primary or metastatic hepatic disease, traditionally considered unresectable, are currently feasible and have been demonstrated to be safe and effective in selected patients [38-41]. Such procedures can be performed in the context of a multimodal approach for patients whose FLR was initially deemed insufficient. These may include initially portal vein embolization (PVE) and subsequent extended liver resection, $1^{\text {st }}$ stage limited resection with concurrent portal vein ligation (PVL), and $2^{\text {nd }}$ stage completion or hepatectomy or associating liver partition and portal vein ligation for staged hepatectomy (ALPPS).

The Clichy group published their experience with 2-stage hepatectomies for NEN patients with synchronous bilobar NELM and initially insufficient FLR [38]. In the $1^{\text {st }}$ stage patients underwent metastatic clearance of FLR alone (13\%), or simultaneous metastatic clearance of FLR and synchronous resection $(87 \%)$ of NEN primary and contralateral PVL, followed by a 2-month interval of monitoring and, in the absence of disease progression, performance of completion hepatectomy. Only $4 \%$ of patients did not proceed to a $2^{\text {nd }}$ stage procedure because of disease progression; $\mathrm{R} 0$ resection was achieved in $75 \%$ of patients. Perioperative morbidity and mortality were $21 \%$ and $0 \%$, respectively. With a median follow up of 64 months, the 2-, 5-, and 8-year OS rates were $94 \%, 94 \%$ and $85 \%$ respectively, whilst 2-, 5-, and 8-year disease-free survival (DFS) rates were $85 \%, 50 \%$ and $26 \%$, respectively. The outcomes of this study, however, should be interpreted with caution, as the patients were highly selected; they were young, slim, with limited or no comorbidities, as 
well as having well-differentiated tumors. However, when such a selection process is applied good long-term outcomes may be achievable. Importantly, a 2-month observation period was adopted, illustrating the need for selecting patients with less aggressive biological tumor behavior. Moreover, the outcomes from the ALPPS registry were recently published, concerning patients with an extensive liver tumor burden not amenable to conventional resection [41]. The primary NEN site in these patients included the small bowel $(43 \%)$, pancreas $(33 \%)$, duodenum (5\%), lung (5\%), ovary (5\%), and unknown (10\%), whereas all grades were represented, although most were G1 and G2 tumors. Notably, the vast majority of patients (95\%) presented with type II bilobar NELM (Fig. 1). All patients successfully underwent stage I and stage II procedures, whilst overall and major morbidity (grade $\geq 3 \mathrm{~b}$ Dindo-Clavien) after stage 2 were $52 \%$ and $28 \%$, respectively [42]. One late death was noted after a stage 2 procedure. During a median follow up of 28 months, 1- and 2-year OS rates were both $95.2 \%$, while 1 - and 2 -year DFS was $73.2 \%$ and $41.8 \%$, respectively. Based on their outcomes, the authors consider G3 NENs as a contraindication for performing ALPPS, while they recommend the performance of a preoperative liver biopsy to rule out any discrepancy in Ki67 expression between primary and NELM tumors, which could lead to futile resection of high-risk patients with a low expected survival benefit [41].

\section{Simultaneous primary and NELM resection}

Contrary to simultaneous resections for other tumors, such as colorectal cancer (CRC) and CRC liver metastases (CRCLM) [43,44], the safety and efficacy of such an approach in the case of primary NEN and synchronous NELM have not been extensively addressed and clinical data are limited $[22,45,46]$. Additionally, whether resections in these patients should be performed in 1 or 2 stages remains illdetermined, as no relevant comparative studies have been published, whereas such prospective randomization of patients is highly improbable at this stage.

In a small case series from Germany, 7 of 19 patients with panNENs who presented with synchronous NELM underwent simultaneous resections; 3 of them underwent R0, one R1 and 3 R2 resections [46]. During a median follow up of 30.5 months, the survival of patients who underwent simultaneous resection was significantly better than that of 12 patients who did not $(\mathrm{P}=0.026)$. Furthermore, the Memorial Sloan-Kettering group reported outcomes from 36 patients with different NEN primaries who underwent simultaneous resection of primary and NELM tumors [45]. Overall, postoperative morbidity and 90 -day mortality were $42 \%$ and $3 \%$, respectively. Six of 16 patients had a postoperative complication grade $\geq 3$ according to Dindo-Clavien. R0, R1 and R2 rates of 36\%, 31\% and $33 \%$ were achieved, with 1 - and 5 -year OS rates of $94 \%$ and $69 \%$, respectively. The authors concluded that synchronous resections are safe and feasible with acceptable long-term outcomes; however, patient selection is of paramount importance. In a recent series, short- and long-term outcomes following simultaneous resection of SI-NENs and NELM were assessed [22]. Thirty-four patients underwent simultaneous resections whilst 10 had unresectable NELM. Overall and major morbidity (grade $\geq 3$ Dindo-Clavien) were $28 \%$ and $11 \%$, respectively, whereas no perioperative deaths were reported. Three-, 5- and 10-year OS rates in patients with unresectable NELM were $34 \%, 33 \%$ and $33 \%$, respectively and were demonstrated to be significantly lower than the equivalent of those who successfully underwent simultaneous resections (93\%, 89\% and 66\%, respectively; $\mathrm{P}=0.0008$ ) [22].

Despite emerging evidence that simultaneous resections are safe in terms of morbidity and perioperative mortality, as well as effective in achieving complete resection and adequate long-term survival, the exact subset of patients who may benefit from such an approach remains undetermined. Notably, patients deemed eligible to undergo such resections, besides being generally fit and without severe comorbidities, should be highly selected with regard to liver involvement (type I or limited bilobar NELM) and thus should not require extensive or complex liver resections, similarly to simultaneous resections for other indications [47].

\section{Debulking surgery}

Cytoreductive or debulking surgery has been proposed as an alternative palliative approach to locoregional liver-directed modalities, either for patients with uncontrollable functional NENs or for those with non-functional NENs and stable disease for an interval of 6 months, with symptomatology attributed to tumor burden $[2,48]$. Cytoreductive surgery may include surgical resection, radiofrequency ablation (RFA), cryoablation or a combination, with the aim of removing $70-90 \%$ of NELM load and thus relieving associated NELMrelated symptoms [18]. The potentially beneficial role of this approach was explored in the early 90 s by the Mayo Clinic group [49]; the indications for gross surgical resection were symptomatic endocrinopathy and symptomatology caused by the primary tumor in $80 \%$ and $20 \%$ of the included patients, respectively, and a 50\% relief of symptoms was reported following cytoreduction. A number of studies, however, with limited numbers of patients, have evaluated the survival benefit of debulking surgery and have shown that achieving acceptable long-term outcomes with such an approach is feasible in selected patients [18,50-52]. An international multicenter study, which included 179 patients who underwent R2/cytoreductive surgery mainly for symptomatic disease (74.9\%), showed a median 5-year OS of $60.7 \%$ months [51]. Even though these patients more commonly had multiple negative prognostic factors, such as synchronous disease, bilateral NELM and lymph node metastasis, reasonable long-term outcomes were achieved. However, the contemporary literature provides no evidence from randomized trials to support the role of palliative cytoreductive surgery in non-resectable NELM of GEP origin [18].

The threshold for liver debulking of NELM has been a matter of debate. With the aim of increasing the number of patients 
eligible for such procedure, a number of studies have evaluated whether achieving less than the standard $90 \%$ tumor debulking is adequate $[23,52,53]$. In a series of panNENs and SI-NENs, one group showed that $>70 \%$ of NELM reduction was associated with significantly higher OS and progression-free survival (PFS) [23]. Another group that adopted a 70\% threshold for patients with carcinoid NELM demonstrated a 5-year disease-specific survival of $90 \%$ [53]. The authors showed that the percentage of NELM resected $(\geq 70 \%)$ was not independently prognostic for survival. Applying the $70 \%$ cytoreduction threshold in NELMs from pancreatic origin, a 5-year OS rate of $81 \%$ was achieved, whilst no significant differences in patient outcomes were evident, based on NELM percentage cytoreduction [53].

\section{Liver transplantation}

In view of the well-established and effective role of orthotopic liver transplantation (OLT) in the treatment of hepatobiliary malignancies in the context of cirrhosis, increased interest has been focused on expanding its use in the management of highly selected patients with unresectable NELM [54]. Several singleand multicenter, and registry studies have published in the last 15 years on the implementation of OLT for patients with unresectable NELM; however, they have yielded conflicting results. Notably, there is a remarkable heterogeneity of patient numbers, patient cohorts and selection criteria, which in turn is reflected in 5-year OS ranging from 30\% to almost 100\%, and a 5-year DFS ranging from 10-90\% [55-65].

Multivariate analysis of NEN patients undergoing OLT by the European liver transplant registry (ELTR) since 2000 identified hepatomegaly, age more than 45 years, and any amount of resection concurrent with OLT as predictors of a poor outcome [58]. Owing to conflicting data on the implications of the Ki67\% LI, a meta-analysis of the four largest OLT series in NENs has been conducted and provides evidence regarding the prognostic value of the Ki67 LI with respect to survival and recurrence. Indeed, only $17 \%$ of patients with $\mathrm{Ki} 67 \% \mathrm{LI}$ $<2 \%$ were free from recurrence at 3 years, compared to $52 \%$ of patients with Ki67\% LI >2\% [66]. However, the probability of escaping NELM recurrence despite maximal radicality is close to zero after more than 5 years.

A number of selection criteria for OLT emerged over the past 2 decades (Table 2) [2,67]. The aim of more strict patient selection is to offer a "curative" treatment that translates into the best possible survival outcome, rather than just a palliative option [59]. The Milan group compared the outcomes of 42 highly selected patients who fulfilled their criteria and subsequently underwent OLT to those of 46 who received other treatments according to non-transplant strategies [59]. During a long-term follow up of over 10 years, OLT patients presented significantly better OS compared to non-OLT patients at 5 and 10 years, with $97.2 \%$ vs. $50.9 \%$ and $88.9 \%$ vs. $22.4 \%$, respectively $(\mathrm{P}<0.001)$ [59].

A recent study identified SI-NEN patients who satisfied the Milan criteria but underwent multimodal treatment instead, according to standardized clinical protocols as per ENETS
Table 2 Selection criteria for consideration for OLT for NELM

\begin{tabular}{|c|c|}
\hline Milan & $\begin{array}{l}\text { - Age }<55 \text { years } \\
\text { - Confirmed histology of low-grade neuroendocrine } \\
\text { tumors (G1/G2) with or without the presence of } \\
\text { syndrome } \\
\text { - Primary tumor drained by the portal system } \\
\text { (pancreas and intermediate gut: from distal stomach } \\
\text { to sigmoid colon) already removed with a curative } \\
\text { resection (removal of all extra-hepatic tumor deposits } \\
\text { prior to OLT) } \\
\text { - Involvement of }<50 \% \text { hepatic parenchyma } \\
\text { - Good response to therapies/stable disease during the } \\
\text { pre-OLT period (at least } 6 \text { months) }\end{array}$ \\
\hline ENETS & $\begin{array}{l}\text { - Young patients ( }<55 \text { years) } \\
\text { - Well-differentiated NEN (G1/G2) with Ki67 } \\
\text { proliferation index } \leq 10 \% \\
\text { - Involvement of }<50 \% \text { hepatic parenchyma or }<75 \% \text { in } \\
\text { cases with refractory hormonal symptoms } \\
\text { - Primary tumor removed prior to OLT (at least } 6 \\
\text { months) } \\
\text { - Stable disease for at least } 6 \text { months } \\
\text { - Robust exclusion of extrahepatic disease by optimized } \\
\text { staging (cross-sectional and functional imaging) } \\
\text { - Low serum total bilirubin }\end{array}$ \\
\hline UNOS & $\begin{array}{l}\text { - Age }<55 \text { years } \\
\text { - Primary tumor drained by the portal system } \\
\text { - Involvement of }<50 \% \text { hepatic parenchyma } \\
\text { - Resected primary tumor and all extra-hepatic tumor } \\
\text { deposits } \\
\text { - Good response to therapies/stable disease during the } \\
\text { pre-OLT period (minimum of } 6 \text { months) } \\
\text { - No extrahepatic disease, bilobar NELM, not amenable } \\
\text { to resection }\end{array}$ \\
\hline
\end{tabular}

OLT, orthotopic liver transplantation; NELM, neuroendocrine liver metastases; ENETS, European Neuroendocrine Tumor Society;

NET, neuroendocrine tumor; UNOS, United Network For Organ Sharing

guidelines, with none of the included patients being referred for OLT. Strikingly, for patients who fulfilled the Milan criteria and received standardized multimodal treatment, the 5-year OS was $97 \%$ [68]. It is noteworthy that, using strict selection criteria and contemporary methods of NELM assessment, there is a substantial risk of underestimating the extent of the liver tumor burden and at the same time over-selecting G1 patients, who might exhibit prime results following OLT, but most probably do not need it $[24,69]$. Nevertheless, given that the worldwide donor pool is relatively small, the use of already limited deceased donor grafts for patients with expanded novel indications remains equivocal [70]. Special reference should finally be made to the use of live donor liver transplantation (LDLT), which has been advocated as an effective alternative approach for these patients, primarily providing encouraging outcomes and secondarily overcoming the ethical challenge of providing grafts to patients with more novel indications, such as NELM $[54,70]$.

\section{Surgery for recurrent NELM}

Recurrent disease is commonly encountered in patients following surgical resection of their NELM at as high a rate as 
$65-90 \%$, largely depending on the origin of the NEN primary and the NELM tumor load (Table 1) [2,71,72]. Although studies have shown that repeat liver resections for recurrent primary or secondary liver lesions are safe and feasible in selected patients with limited hepatic involvement [73-75], data on the outcomes of such an approach for recurrent NELM (rNELM) are limited [71,72]. A retrospective, international multicenter study, which evaluated patients with recurrent disease following curative-intent liver surgery for NELM, showed a $65.7 \%$ intrahepatic-only recurrence rate. Patients with liver-only recurrence were more commonly those with non-functional primaries of GEP origin, moderately differentiated, initially diagnosed with synchronous disease, having undergone R1 resections, $\geq 50 \%$ liver involvement and those who underwent concurrent intraoperative tumor ablation [71]. Repeat liver resection was feasible in $43.8 \%$ of patients with rNELM, demonstrating that patients who underwent surgery in the whole cohort had better 10-year OS compared to those receiving intra-arterial therapies, somatostatin analogs or chemotherapy $(\mathrm{P}=0.001)[71]$. A more recent study from Japan analyzed data from 33 patients who initially underwent resection for NELM, $85 \%$ of whom presented with rNELM [72]. Sixteen patients $(48.4 \%)$ with rNELM underwent repeat liver resection and their 5-year OS was significantly higher than those who did not (78.6\% vs. $35.4 \%, \mathrm{P}<0.001$ ).

From these data it appears that roughly $45 \%$ of patients with rNELM are amenable to repeat liver resection, whilst survival of these patients was equal or longer compared to those undergoing primary liver resection. One could therefore argue that, in order to maximize the percentage of patients with recurrent disease who reach surgery, more intense follow-up planning should be implemented in patients at higher risk for recurrence, including cross-sectional and functional imaging strategies, to identify and accurately define recurrent disease at an earlier stage and potentially offer repeat surgery if feasible.

\section{Non-surgical liver-targeted treatments}

\section{Ablative techniques (RFA and other ablative techniques)}

RFA is a localized thermal treatment technique designed to induce tumor destruction by heating the tumor tissue to temperatures that exceed $60^{\circ} \mathrm{C}$, achieving coagulative necrosis [76,77]. RFA is performed either percutaneously under imaging guidance (computed tomography [CT] or ultrasonography), or intraoperatively in combination with hepatic resection using either open or laparoscopic approaches. It is generally indicated for limited NELM $<5 \mathrm{~cm}$ in size when surgery is contraindicated, or in combination with liver resection in cases of bilobar extension to limit the extent of hepatectomy. On the other hand, RFA is usually contraindicated for NELM around vital structures in the liver hilum, superficial NELM, or if the patient has had a previous Whipple procedure [78]. Crosssectional imaging with CT or magnetic resonance imaging is commonly applied post-treatment to determine complete tumor necrosis [79]. In several studies, RFA has been confirmed as a relatively safe and well-tolerated procedure with a wide range of patient outcomes in terms of OS and PFS [80-82]. Importantly, apart from RFA's complementary role to liver surgery, special attention should be given to its role in NEN cytoreduction and control of hormonal syndromes. RFA can also be effectively combined with surgical resection in an effort to preserve the highest possible percentage of hepatic parenchyma. Studies assessing outcomes from patients undergoing resection and concomitant ablation of NELM have documented equally good long-term outcomes [83-85]. Reported complications after RFA include portal vein thrombosis, hemoperitoneum, viscus perforation, bile leak, liver abscess, pneumothorax and pleural effusions $[78,82]$. Furthermore, RFA mandates a high level of operator experience in the use of conventional ultrasoundand CT-navigation in order to achieve precise $3 \mathrm{D}$ alignment of probes and subsequently create adequately overlapping ablation areas. In that setting, stereotactic RFA as an emerging alternative approach allows for optimal 3D ablation planning and achievement of optimal configuration of the RFA probes, thus creating multiple overlapping coagulation volumes, especially in larger tumors $(>5 \mathrm{~cm})$ [86].

Microwave ablation (MWA) has also been confirmed as an effective and relatively safe, minimally invasive technique in hepatocellular carcinomas and colorectal LM [87]. MWA is able to achieve prime results compared to RFA, i.e., larger ablation zones and less heat-sink effect $[88,89]$. Recently, MWA has been utilized in NELM management with promising results, as an alternative or supplement to hepatic resection, with high local efficiency, modest toxicity and favorable short-term local tumor control rates compared to RFA [90,91]. Combined treatments of intraoperative MWA and surgical resection represent interesting strategies that allow complete parenchyma-sparing approaches for otherwise unresectable NELM, potentially in the setting of a 2-staged hemi-hepatectomy.

\section{TAE and TACE}

A characteristic feature of NELM is their hypervascularity and enhanced arterial rather than portal blood supply. TAE by intravascular delivery of embolic agents through selective catheterization of the hepatic artery has been developed to induce tumor ischemia and necrosis. As embolization reduces the blood flow to the targeted NELM, TACE can also be applied, favoring a higher local drug concentration and retention by NELM [92-94]. Cytotoxics used with TACE include either doxorubicin or streptozotocin in mixtures with lipiodol [95]. In contrast to patients selected for RFA/MWA, TAE/TACE is mostly indicated for patients with multiple nonresectable NELM and a more advanced liver tumor burden [2]. Intra-arterial embolization techniques are generally contraindicated in the presence of portal vein thrombosis, hepatic insufficiency or bilio-enteric anastomosis. NEN patient outcomes on TAE or TACE are presented in Supplementary Table 1. However, the available literature on these techniques is derived from mostly underpowered retrospective studies with certain biases, including heterogeneity in embolization 
methodology. Symptom regression, tumor response rate according to Response Evaluation Criteria in Solid Tumors (RECIST), and survival outcomes after TAE/TACE varied greatly in the included studies, precluding the drawing of any safe conclusions. No available evidence exists that one transarterial technique is superior to the other in terms of anti-tumor efficacy; however, TAE may be rather safer than TACE $[96,97]$. Further comparative prospective studies are warranted to determine whether TAE/TACE potentially offer an advantage over surgical cytoreduction and/or PRRT in terms of PFS and preservation of health-related quality of life.

With regards to staged resections for extensive disease, preoperative PVE has been proposed to induce compensatory hypertrophy of the contralateral FLR, as previously discussed. Interestingly, in the setting of unilobar hepatocellular carcinoma, sequential selective TACE and PVE before major liver resection have been applied to increase the rate of FLR hypertrophy, resulting in a high rate of complete tumor necrosis associated with longer recurrence-free survival [98]. However, the role of the preoperative combination of TACE and PVE in NELM has not yet been assessed. Furthermore, the clinical utility of combinations of embolization and systemic NEN therapies remains to be explored.

Regarding the safetyprofile ofTAE/TACE, post-embolization syndrome with abdominal pain, nausea, fever, hypertension, leukocytosis, thrombocytopenia, hypertransaminasemia, and an increase in lactate dehydrogenase have been reported in up to $90 \%$ of treated patients $[79,99]$. Other complications include liver necrosis, renal insufficiency, liver abscess and ischemic complications of the stomach and the gallbladder.

\section{RE}

$\mathrm{RE}$ is based on the percutaneous transarterial administration of micro-sized embolic particles connected with a radioisotope, commonly Yttrium-90 microspheres (Thera-Sphere) or resin (SIR-Spheres). RE may target multiple NELM [92]. This technique aims at delivering therapeutic radiation to NELM, while sparing normal parenchyma. Like TAE and TACE, RE is generally indicated in patients with NELM not amenable to hepatic resection as per ENETS guidelines [2]. Symptom control, tumor response rates and survival outcomes after RE varied significantly in relevant studies, with comparable figures to TAE/TACE administration; although RE seems to have a favorable safety profile more studies are needed on long-term toxicities and overall RE tolerability $[2,100,101]$. In particular, abdominal pain, nausea, fever and fatigue may occur in the short term, whereas hepatotoxicity and radiation- gastritis and pneumonitis may complicate RE administration later on in the disease course [102,103].

Importantly, in selected cases, liver resection may be possible post RE, as depicted in a recent study of NELM and other malignancies [104]. Therefore, it may be prudent to reconsider hepatectomy in patients undergoing transarterial embolization modalities. It should be noted that postoperative complications following major and extended liver resections in this setting need to be thorougly considered in surgical planning.

\section{PRRT}

PRRT is a therapeutic approach that uses $\beta$-emission radiation to induce tumor necrosis. PRRT agents for NELM consist of a chelator attached to a somatostatin receptor (SSTR) ligand, such as $\left[\mathrm{Tyr}^{3}\right]$ octreotide or $\left[\mathrm{Tyr}^{3}\right]$ octreotate, and a radionuclide, such as Yttrium-90 $\left({ }^{90} \mathrm{Y}\right)$ or Lutetium-177 $\left({ }^{177} \mathrm{Lu}\right)[105]$.

The most important indications for PRRT include lowergrade NELM and extra-hepatic metastases (grades 1 and 2) with sufficient SSTR expression on diagnostic SSTR scintigraphy in patients with adequate renal function and bone marrow reserves [106]. In addition, dual tracer using 18F-fluorodeoxyglucose (18F-FDG) positron emission tomography/CT and SSTR scintigraphy may provide important information for patient selection for PRRT in the heterogeneous complex high-grade disease group of G3 NEN and NECs [107].

PRRT, irrespective of the radionuclide or peptide used, seems to be an effective therapy for NENs, as exhibited in several retrospective studies and prospective trials, where the tumor response rate ranged between $74 \%$ and $100 \%$ for ${ }^{177} \mathrm{Lu}$-DOTATATE and ${ }^{90} \mathrm{Y}$-DOTATOC. Favorable PFS and OS figures have also been demonstrated. Patient outcomes from NEN studies on PRRT are presented in Supplementary Table 2. Importantly, the efficacy and safety of PRRT in the management of metastatic SI-NENs with progressive disease was confirmed in the NETTER-1 randomized controlled trial [108]. Although in most studies assessment of the treatment response occurred at all sites, many patients had undergone resection of the primary and the liver was the dominant site of metastases assessed by RECIST criteria. Although no randomized PRRT trial has been conducted in pancreatic and lung NENs as yet, the efficacy of PRRT in these subsets of NENs has been confirmed in retrospective studies with real-world data, also in the setting of patients heavily pretreated with chemotherapy [109-111].

In addition, resection of the primary tumor followed by PRRT has been safely proposed as an upfront strategy for the treatment of G1-G2 PanNENs with diffuse unresectable NELM, because it seems to enhance the response to PRRT and to improve PFS significantly [112]. Accordingly, combining PRRT and RE has been suggested in NEN patients with bulky NELM or those with a predominant liver tumor burden and extrahepatic disease, since PRRT results in a limited response in bulky NELM compared to a miliary metastatic pattern [113]. Despite concerns about cumulative hepatotoxicity, RE following PPRT was a safe sequence as a salvage option, with RE-induced liver disease occurring only rarely [113-115].

PRRT agents' toxicity profiles are generally modest, but can sometimes include life-threatening events of myelotoxicity, hepatic and renal failure [106,116]. Although the risk of therapy-related myeloid neoplasm after PRRT is small, close monitoring is warranted to identify such patients early in the disease course when hematologic abnormalities persist [117]. 


\section{Ongoing trials}

Several ongoing trials are aiming to elucidate the optimal management for patients with non-operable NELM. The LUTIA trial (NCT03590119) is a multicenter, interventional, block randomized, phase 2 clinical trial in which patients with NELM were randomized to administration of ${ }^{177} \mathrm{Lu}$-dotatate between the right or left hepatic artery. Selective intra-arterial administration of ${ }^{177} \mathrm{Lu}$-dotatate will potentially allow for intra-patient comparison between intra-arterial administration (one lobe) vs. intravenous (IV) "administration" (contralateral lobe). Another trial (NCT02724540) is recruiting patients with unresectable NELM and randomizing them to bland embolization, TACE, and embolization by drug-eluting beads, aiming to estimate the duration of hepatic PFS in each arm. Another multicenter trial from the US (NCT03724409) is recruiting patients with NELM deriving from SI-NENs, not amenable to other therapies (surgery, ablation), which have progressed after treatment with octreotide/ lanreotide and/or other treatments, and randomizing them to several different [90]Y-DOTATOC dosages administered intraarterially to the liver. The NCT03457948 trial is a four-arm, openlabel non-randomized pilot study recruiting biomarker nonselected patients with NELM from G1/G2 NEN initially treated with pembrolizumab. Patients with up to 6 liver lesions (maximum $4 \mathrm{~cm}$ ) will be treated with RFA or cryoablation, patients with up to $75 \%$ involvement of hepatic parenchyma and largest lesion up to 5 $\mathrm{cm}$ will be treated with subsegmental embolization, while patients with up to $75 \%$ involvement and largest lesion larger than $5 \mathrm{~cm}$ will receive subsegmental Yttrium-90 RE. Finally, study NCT0388306 is a prospective trial recruiting patients with unresectable NELM to evaluate the safety and effectiveness of TACE using CalliSpheres drug-eluting beads with oxaliplatin (DEBOXA). In addition, the COMPET trial (NCT03049189), a phase 3 study of the efficacy and safety of ${ }^{177} \mathrm{Lu}$-edotreotide PRRT in NELM from GEP origin, the phase 2 EVACEL trial (NCT01678664) of everolimus after TACE for NELM, the phase 2 OCCLURANDOM study (NCT02230176) of ${ }^{177}$ Lutetium-octreotate PRRT randomized versus sunitinib in NELM of pancreatic origin, and the phase 1 NCT03724409 trial of selective intra-arterial injection of PRRT for NELM are all eagerly anticipated.

\section{Concluding remarks}

Surgical resection remains the cornerstone in the management of selected patients with NELM whenever feasible. The combination of advances in surgical techniques and improvements in patient selection during the past decades has remarkably transformed relevant long-term outcomes. Complex liver surgery for primary or recurrent NELMs is currently widely performed, equally safely and effectively for patients with extensive disease previously deemed unresectable, whilst OLT, under strict criteria, represents a potentially curative treatment option rather than a palliative option.

Interventional radiology liver-targeted modalities for NELM can be used alone or in combination with liver-directed surgical techniques and generally precede systemic treatments in patients with liver-dominant metastatic NEN disease, as indicated per patient. Apart from control of hormonal syndromes with reduced treatment-related toxicities, special attention should be given to the potential use of these techniques as neoadjuvant cytoreduction and bridging to liver surgery for NEN patients with NELM previously deemed inoperable. In addition, in the setting of recurrent NELM necessitating repeated treatments not amenable to re-resection, these minimally invasive techniques may offer a safe alternative.

Prospective clinical trials in more homogeneous cohorts of NEN patients are warranted to further elucidate the optimal sequencing of these treatment modalities and their potential combination with systemic agents. Finally, combinations of sequencing and imaging data are expected to allow for a better tumor characterization and therefore improved selection of the appropriate treatment protocol on an individual patient basis.

\section{References}

1. Modlin IM, Oberg K, Chung DC, et al. Gastroenteropancreatic neuroendocrine tumours. Lancet Oncol 2008;9:61-72.

2. Pavel M, O’Toole D, Costa F, et al; Vienna Consensus Conference participants. ENETS consensus guidelines update for the management of distant metastatic disease of intestinal, pancreatic, bronchial neuroendocrine neoplasms (NEN) and NEN of unknown primary site. Neuroendocrinology 2016;103:172-185.

3. Hofland J, Kaltsas G, de Herder WW. Advances in the diagnosis and management of well-differentiated neuroendocrine neoplasms. Endocr Rev 2020;41:371-403.

4. Dasari A, Shen C, Halperin D, et al. Trends in the incidence, prevalence, and survival outcomes in patients with neuroendocrine tumors in the United States. JAMA Oncol 2017;3:1335-1342.

5. Pape UF, Berndt U, Müller-Nordhorn J, et al. Prognostic factors of long-term outcome in gastroenteropancreatic neuroendocrine tumours. Endocr Relat Cancer 2008;15:1083-1097.

6. Frilling A, Clift AK. Therapeutic strategies for neuroendocrine liver metastases. Cancer 2015;121:1172-1186.

7. Yao JC, Hassan M, Phan A, et al. One hundred years after "carcinoid": epidemiology of and prognostic factors for neuroendocrine tumors in 35,825 cases in the United States. J Clin Oncol 2008;26:3063-3072.

8. Norlén O, Stålberg P, Öberg K, et al. Long-term results of surgery for small intestinal neuroendocrine tumors at a tertiary referral center. World J Surg 2012;36:1419-1431.

9. Modlin IM, Lye KD, Kidd M. A 5-decade analysis of 13,715 carcinoid tumors. Cancer 2003;97:934-959.

10. Frilling A, Modlin IM, Kidd M, et al; Working Group on Neuroendocrine Liver Metastases. Recommendations for management of patients with neuroendocrine liver metastases. Lancet Oncol 2014;15:e8-e21.

11. Lawrence B, Gustafsson BI, Chan A, Svejda B, Kidd M, Modlin IM. The epidemiology of gastroenteropancreatic neuroendocrine tumors. Endocrinol Metab Clin North Am 2011;40:1-18.

12. Panzuto F, Nasoni S, Falconi M, et al. Prognostic factors and survival in endocrine tumor patients: comparison between gastrointestinal and pancreatic localization. Endocr Relat Cancer 2005;12:1083-1092.

13. Frilling A, Li J, Malamutmann E, Schmid KW, Bockisch A, Broelsch CE. Treatment of liver metastases from neuroendocrine tumours in relation to the extent of hepatic disease. Br J Surg 
2009;96:175-184

14. Cives M, Strosberg J. Treatment strategies for metastatic neuroendocrine tumors of the gastrointestinal tract. Curr Treat Options Oncol 2017;18:14.

15. Ioannidis A, Konstantinidis M, Apostolakis S, Koutserimpas C, Machairas N, Konstantinidis KM. Impact of multidisciplinary tumor boards on patients with rectal cancer. Mol Clin Oncol 2018;9:135-137.

16. Colquhoun S. Neuroendocrine tumors with hepatic metastases: a review of evolving treatment options. Liver Res 2018;2:92-99.

17. Nigri G, Petrucciani N, Debs T, et al. Treatment options for PNET liver metastases: a systematic review. World J Surg Oncol 2018;16:142.

18. Gurusamy KS, Pamecha V, Sharma D, Davidson BR. Palliative cytoreductive surgery versus other palliative treatments in patients with unresectable liver metastases from gastro-enteropancreatic neuroendocrine tumours. Cochrane Database Syst Rev 2009;2009:CD007118.

19. Gurusamy KS, Ramamoorthy R, Sharma D, Davidson BR. Liver resection versus other treatments for neuroendocrine tumours in patients with resectable liver metastases. Cochrane Database Syst Rev 2009;2009:CD007060

20. Norlén O, Stålberg P, Zedenius J, Hellman P. Outcome after resection and radiofrequency ablation of liver metastases from small intestinal neuroendocrine tumours. Br J Surg 2013;100: 1505-1514.

21. Clift AK, Frilling A. Management of patients with hepatic metastases from neuroendocrine tumors. Ann Saudi Med 2014;34:279-290.

22. Addeo P, Bertin JB, Imperiale A, et al. Outcomes of simultaneous resection of small bowel neuroendocrine tumors with synchronous liver metastases. World J Surg 2020;44:2377-2384.

23. Maxwell JE, Sherman SK, O’Dorisio TM, Bellizzi AM, Howe JR. Liver-directed surgery of neuroendocrine metastases: What is the optimal strategy? Surgery 2016;159:320-333.

24. Elias D, Lefevre JH, Duvillard P, et al. Hepatic metastases from neuroendocrine tumors with a "thin slice" pathological examination: they are many more than you think. Ann Surg 2010;251:307-310.

25. Saxena A, Chua TC, Zhao J, Morris DL. Liver-directed therapy for neuroendocrine neoplasm hepatic metastasis prolongs survival following progression after initial surgery. J Surg Oncol 2012;105:342-350

26. Saxena A, Chua TC, Perera M, Chu F, Morris DL. Surgical resection of hepatic metastases from neuroendocrine neoplasms: a systematic review. Surg Oncol 2012;21:e131-e141.

27. Sahara K, Merath K, Tsilimigras DI, et al. Conditional disease-free survival after curative-intent liver resection for neuroendocrine liver metastasis. J Surg Oncol 2019;120:1087-1095.

28. Masui T, Nagai K, Anazawa T, et al. Risk factors for short recurrence-free survival after resection of pancreatic neuroendocrine tumor (PanNET) liver metastases: which patients should undergo resection? Scand J Gastroentrol 2020:1-6.

29. Ruzzenente A, Bagante F, Bertuzzo F, et al. A Novel Nomogram to Predict the Prognosis of Patients Undergoing Liver Resection for Neuroendocrine Liver Metastasis: an Analysis of the Italian Neuroendocrine Liver Metastasis Database. J Gastrointest Surg 2017;21:41-48

30. Mayo SC, de Jong MC, Pulitano C, et al. Surgical management of hepatic neuroendocrine tumor metastasis: results from an international multi-institutional analysis. Ann Surg Oncol 2010;17:3129-3136.

31. Saxena A, Chua TC, Sarkar A, et al. Progression and survival results after radical hepatic metastasectomy of indolent advanced neuroendocrine neoplasms (NENs) supports an aggressive surgical approach. Surgery 2011;149:209-220.

32. Hibi T, Sano T, Sakamoto Y, et al. Surgery for hepatic neuroendocrine tumors: a single institutional experience in Japan. Jpn J Clin Oncol 2007;37:102-107

33. Reddy SK, Barbas AS, Marroquin CE, Morse MA, Kuo PC, Clary BM. Resection of noncolorectal nonneuroendocrine liver metastases: a comparative analysis. J Am Coll Surg 2007;204: 372-382.

34. Sarmiento JM, Heywood G, Rubin J, Ilstrup DM, Nagorney DM, Que FG. Surgical treatment of neuroendocrine metastases to the liver: a plea for resection to increase survival. J Am Coll Surg 2003;197:29-37.

35. Chamberlain RS, Canes D, Brown KT, et al. Hepatic neuroendocrine metastases: does intervention alter outcomes? J Am Coll Surg 2000;190:432-445.

36. Kaçmaz E, Heidsma CM, Besselink MGH, et al. Treatment of liver metastases from midgut neuroendocrine tumours: a systematic review and meta-analysis. J Clin Med 2019;8:403.

37. Yu X, Gu J, Wu H, Fu D, Li J, Jin C. Resection of liver metastases: a treatment provides a long-term survival benefit for patients with advanced pancreatic neuroendocrine tumors: a systematic review and meta-analysis. J Oncol 2018;2018:6273947.

38. Kianmanesh R, Sauvanet A, Hentic O, et al. Two-step surgery for synchronous bilobar liver metastases from digestive endocrine tumors: a safe approach for radical resection. Ann Surg 2008;247:659-665.

39. Albati NA, Korairi AA, Hasan IA, Almodhaiberi HK, Algarni AA. Outcomes of staged hepatectomies for liver malignancy. World J Hepatol 2019;11:513-521.

40. Baili E, Tsilimigras DI, Filippou D, et al. Associating liver partition and portal vein ligation for staged hepatectomy in patients with primary liver malignancies: A systematic review of the literature. J BUON 2019;24:1371-1381.

41. Linecker M, Kambakamba P, Raptis DA, et al. ALPPS in neuroendocrine liver metastases not amenable for conventional resection - lessons learned from an interim analysis of the International ALPPS Registry. HPB (Oxford) 2020;22:537-544.

42. Clavien PA, Barkun J, de Oliveira ML, et al. The Clavien-Dindo classification of surgical complications: five-year experience. Ann Surg 2009;250:187-196.

43. Reddy SK, Pawlik TM, Zorzi D, et al. Simultaneous resections of colorectal cancer and synchronous liver metastases: a multiinstitutional analysis. Ann Surg Oncol 2007;14:3481-3491.

44. Moris D, Tsilimigras DI, Machairas N, et al. Laparoscopic synchronous resection of colorectal cancer and liver metastases: A systematic review. J Surg Oncol 2019;119:30-39.

45. Gaujoux S, Gonen M, Tang L, et al. Synchronous resection of primary and liver metastases for neuroendocrine tumors. Ann Surg Oncol 2012;19:4270-4277.

46. Schurr PG, Strate T, Rese K, et al. Aggressive surgery improves long-term survival in neuroendocrine pancreatic tumors: an institutional experience. Ann Surg 2007;245:273-281.

47. Adam R, de Gramont A, Figueras J, et al; of the EGOSLIM (Expert Group on OncoSurgery management of LIver Metastases) group. Managing synchronous liver metastases from colorectal cancer: a multidisciplinary international consensus. Cancer Treat Rev 2015;41:729-741.

48. Tsoli M, Chatzellis E, Koumarianou A, Kolomodi D, Kaltsas G. Current best practice in the management of neuroendocrine tumors. Ther Adv Endocrinol Metab 2019;10:2042018818804698.

49. McEntee GP, Nagorney DM, Kvols LK, Moertel CG, Grant CS. Cytoreductive hepatic surgery for neuroendocrine tumors. Surgery 1990;108:1091-1096.

50. Osborne DA, Zervos EE, Strosberg J, et al. Improved outcome with cytoreduction versus embolization for symptomatic hepatic 
metastases of carcinoid and neuroendocrine tumors. Ann Surg Oncol 2006; 13:572-581.

51. Ejaz A, Reames BN, Maithel S, et al. Cytoreductive debulking surgery among patients with neuroendocrine liver metastasis: a multi-institutional analysis. HPB (Oxford) 2018;20:277-284.

52. Morgan RE, Pommier SJ, Pommier RF. Expanded criteria for debulking of liver metastasis also apply to pancreatic neuroendocrine tumors. Surgery 2018;163:218-225.

53. Graff-Baker AN, Sauer DA, Pommier SJ, Pommier RF. Expanded criteria for carcinoid liver debulking: Maintaining survival and increasing the number of eligible patients. Surgery 2014;156: 1369-1376.

54. Lerut J, Iesari S, Vandeplas G, et al. Secondary non-resectable liver tumors: A single-center living-donor and deceased-donor liver transplantation case series. Hepatobiliary Pancreat Dis Int 2019;18:412-422.

55. Frilling A, Malago M, Weber F, et al. Liver transplantation for patients with metastatic endocrine tumors: single-center experience with 15 patients. Liver Transpl 2006;12:1089-1096.

56. Bonaccorsi-Riani E, Apestegui C, Jouret-Mourin A, et al. Liver transplantation and neuroendocrine tumors: lessons from a single centre experience and from the literature review. Transpl Int 2010;23:668-678.

57. Gedaly R, Daily MF, Davenport D, et al. Liver transplantation for the treatment of liver metastases from neuroendocrine tumors: an analysis of the UNOS database. Arch Surg 2011;146:953-958.

58. Le Treut YP, Grégoire E, Klempnauer J, et al; For ELITA. Liver transplantation for neuroendocrine tumors in Europe-results and trends in patient selection: a 213-case European liver transplant registry study. Ann Surg 2013;257:807-815.

59. Mazzaferro V, Sposito C, Coppa J, et al. The long-term benefit of liver transplantation for hepatic metastases from neuroendocrine tumors. Am J Transplant 2016;16:2892-2902.

60. Nguyen NT, Harring TR, Goss JA, O'Mahony CA. Neuroendocrine liver metastases and orthotopic liver transplantation: the US experience. Int J Hepatol 2011;2011:742890.

61. Nobel YR, Goldberg DS. Variable use of model for end-stage liver disease exception points in patients with neuroendocrine tumors metastatic to the liver and its impact on patient outcomes. Transplantation 2015;99:2341-2346.

62. Olausson M, Friman S, Herlenius G, et al. Orthotopic liver or multivisceral transplantation as treatment of metastatic neuroendocrine tumors. Liver Transpl 2007;13:327-333.

63. Sher LS, Levi DM, Wecsler JS, et al. Liver transplantation for metastatic neuroendocrine tumors: Outcomes and prognostic variables. J Surg Oncol 2015;112:125-132.

64. van Vilsteren FG, Baskin-Bey ES, Nagorney DM, et al. Liver transplantation for gastroenteropancreatic neuroendocrine cancers: Defining selection criteria to improve survival. Liver Transpl 2006;12:448-456.

65. Máthé Z, Tagkalos E, Paul A, et al. Liver transplantation for hepatic metastases of neuroendocrine pancreatic tumors: a survival-based analysis. Transplantation 2011;91:575-582.

66. Grossman EJ, Millis JM. Liver transplantation for nonhepatocellular carcinoma malignancy: indications, limitations, and analysis of the current literature. Liver Transpl 2010;16:930-942.

67. Mazzaferro V, Pulvirenti A, Coppa J. Neuroendocrine tumors metastatic to the liver: how to select patients for liver transplantation? J Hepatol 2007;47:460-466.

68. Norlen O, Daskalakis K, Oberg K, Akerstrom G, Stalberg P, Hellman P. Indication for liver transplantation in young patients with small intestinal NETs is rare? World J Surg 2014;38:742-747.

69. Pascher A, Klupp J, Neuhaus P. Endocrine tumours of the gastrointestinal tract. Transplantation in the management of metastatic endocrine tumours. Best Pract Res Clin Gastroenterol
2005; 19:637-648.

70. Yankol Y, Mecit N, Kanmaz T, Acarli K, Kalayoglu M. Living donor liver transplantation: a life-saving option in emergency situations for diffuse hepatic neuroendocrine tumor metastasis. Transplant Proc 2015;47:427-430.

71. Spolverato G, Bagante F, Aldrighetti L, et al. Management and outcomes of patients with recurrent neuroendocrine liver metastasis after curative surgery: an international multiinstitutional analysis. J Surg Oncol 2017;116:298-306.

72. Kiritani S, Arita J, Matsumura M, et al. Repeat hepatectomy for patients with recurrent neuroendocrine liver metastasis: comparison with first hepatectomy. Surgery 2020;167:404-409.

73. Kulik U, Bektas H, Klempnauer J, Lehner F. Repeat liver resection for colorectal metastases. Br J Surg 2013;100:926-932.

74. Bartsch F, Paschold M, Baumgart J, Hoppe-Lotichius M, Heinrich S, Lang H. Surgical resection for recurrent intrahepatic cholangiocarcinoma. World J Surg 2019;43:1105-1116.

75. Machairas N, Papaconstantinou D, Stamopoulos P, et al. The emerging role of laparoscopic liver resection in the treatment of recurrent hepatocellular carcinoma: a systematic review. Anticancer Res 2018;38:3181-3186.

76. Rhim H, Lim HK. Radiofrequency ablation of hepatocellular carcinoma: pros and cons. Gut Liver 2010;4(Suppl 1):S113-S118.

77. Minami Y, Kudo M. Radiofrequency ablation of hepatocellular carcinoma: Current status. World J Radiol 2010;2:417-424.

78. Berber E, Tsinberg M, Tellioglu G, Simpfendorfer $\mathrm{CH}$, Siperstein AE. Resection versus laparoscopic radiofrequency thermal ablation of solitary colorectal liver metastasis. $J$ Gastrointest Surg 2008;12:1967-1972.

79. Zappa M, Abdel-Rehim M, Hentic O, Vullierme MP, Ruszniewski P, Vilgrain V. Liver-directed therapies in liver metastases from neuroendocrine tumors of the gastrointestinal tract. Target Oncol 2012;7:107-116.

80. Frilling A, Sotiropoulos GC, Li J, Kornasiewicz O, Plöckinger U. Multimodal management of neuroendocrine liver metastases. HPB (Oxford) 2010;12:361-379.

81. Elias D, Goéré D, Leroux G, et al. Combined liver surgery and RFA for patients with gastroenteropancreatic endocrine tumors presenting with more than 15 metastases to the liver. Eur J Surg Oncol 2009;35:1092-1097.

82. Akyildiz HY, Mitchell J, Milas M, Siperstein A, Berber E. Laparoscopic radiofrequency thermal ablation of neuroendocrine hepatic metastases: long-term follow-up. Surgery 2010;148:1288-1293.

83. Musunuru S, Chen H, Rajpal S, et al. Metastatic neuroendocrine hepatic tumors: resection improves survival. Arch Surg 2006;141:1000-1004.

84. Touzios JG, Kiely JM, Pitt SC, et al. Neuroendocrine hepatic metastases: does aggressive management improve survival? Ann Surg 2005;241:776-783.

85. Landry CS, Scoggins CR, McMasters KM, Martin RC 2nd. Management of hepatic metastasis of gastrointestinal carcinoid tumors. J Surg Oncol 2008;97:253-258.

86. Schullian P, Johnston EW, Putzer D, Eberle G, Laimer G, Bale R. Safety and efficacy of stereotactic radiofrequency ablation for very large $(\geq 8 \mathrm{~cm})$ primary and metastatic liver tumors. Sci Rep 2020;10:1618.

87. Martin RC, Scoggins CR, McMasters KM. Safety and efficacy of microwave ablation of hepatic tumors: a prospective review of a 5-year experience. Ann Surg Oncol 2010;17:171-178.

88. Urbonas T, Anderson EM, Gordon-Weeks AN, et al. Factors predicting ablation site recurrence following percutaneous microwave ablation of colorectal hepatic metastases. HPB (Oxford) 2019;21:1175-1184.

89. Correa-Gallego C, Fong Y, Gonen M, et al. A retrospective comparison of microwave ablation vs. radiofrequency ablation 
for colorectal cancer hepatic metastases. Ann Surg Oncol 2014;21:4278-4283.

90. Perrodin SF, Renzulli MM, Maurer MH, et al. Can microwave ablation be an alternative to resection for the treatment of neuroendocrine liver metastases? Endocr Pract 2019;26:378-387.

91. Takahashi H, Kahramangil B, Berber E. Local recurrence after microwave thermosphere ablation of malignant liver tumors: results of a surgical series. Surgery 2018;163:709-713.

92. Dermine S, Palmieri LJ, Lavolé J, et al. Non-pharmacological therapeutic options for liver metastases in advanced neuroendocrine tumors. J Clin Med 2019;8:1907.

93. Kennedy A, Bester L, Salem R, Sharma RA, Parks RW, Ruszniewski P; NET-Liver-Metastases Consensus Conference. Role of hepatic intra-arterial therapies in metastatic neuroendocrine tumours (NET): guidelines from the NET-LiverMetastases Consensus Conference. HPB (Oxford) 2015;17:29-37.

94. de Baere T, Deschamps F, Tselikas L, et al. GEP-NETS update: Interventional radiology: role in the treatment of liver metastases from GEP-NETs. Eur J Endocrinol 2015;172:R151-R166.

95. Pavel M, Baudin E, Couvelard A, et al; Barcelona Consensus Conference participants. ENETS Consensus Guidelines for the management of patients with liver and other distant metastases from neuroendocrine neoplasms of foregut, midgut, hindgut, and unknown primary. Neuroendocrinology 2012;95:157-176.

96. Fiore F, Del Prete M, Franco R, et al. Transarterial embolization (TAE) is equally effective and slightly safer than transarterial chemoembolization (TACE) to manage liver metastases in neuroendocrine tumors. Endocrine 2014;47:177-182.

97. Maire F, Lombard-Bohas C, O'Toole D, et al. Hepatic arterial embolization versus chemoembolization in the treatment of liver metastases from well-differentiated midgut endocrine tumors: a prospective randomized study. Neuroendocrinology 2012;96:294-300.

98. Ronot M, Cauchy F, Gregoli B, et al. Sequential transarterial chemoembolization and portal vein embolization before resection is a valid oncological strategy for unilobar hepatocellular carcinoma regardless of the tumor burden. HPB (Oxford) 2016;18:684-690.

99. Del Prete M, Fiore F, Modica R, et al; Multidisciplinary Group for NeuroEndocrine Tumors of Naples. Hepatic arterial embolization in patients with neuroendocrine tumors. J Exp Clin Cancer Res 2014;33:43

100. Kennedy AS, Dezarn WA, McNeillie P, et al. Radioembolization for unresectable neuroendocrine hepatic metastases using resin 90Y-microspheres: early results in 148 patients. Am J Clin Oncol 2008;31:271-279.

101. Elf AK, Andersson M, Henrikson O, et al. Radioembolization versus bland embolization for hepatic metastases from small intestinal neuroendocrine tumors: short-term results of a randomized clinical trial. World J Surg 2018;42:506-513.

102. King J, Quinn R, Glenn DM, et al. Radioembolization with selective internal radiation microspheres for neuroendocrine liver metastases. Cancer 2008;113:921-929.

103. Fidelman N, Kerlan RK Jr, Hawkins RA, et al. Radioembolization with ${ }^{90} \mathrm{Y}$ glass microspheres for the treatment of unresectable metastatic liver disease from chemotherapy-refractory gastrointestinal cancers: final report of a prospective pilot study. J Gastrointest Oncol 2016;7:860-874.

104. Mafeld S, Littler P, Hayhurst $\mathrm{H}$, et al. Liver resection after selective internal radiation therapy with yttrium-90: safety and outcomes. J Gastrointest Cancer 2020;51:152-158.

105. van der Zwan WA, Bodei L, Mueller-Brand J, de Herder WW, Kvols LK, Kwekkeboom DJ. GEPNETs update: Radionuclide therapy in neuroendocrine tumors. Eur J Endocrinol 2015;172:R1-R8.

106. Hicks RJ, Kwekkeboom DJ, Krenning E, et al; Antibes Consensus Conference participants. ENETS consensus guidelines for the standards of care in neuroendocrine neoplasia: peptide receptor radionuclide therapy with radiolabeled somatostatin analogues. Neuroendocrinology 2017;105:295-309.

107. Sorbye H, Kong G, Grozinsky-Glasberg S. PRRT in high-grade gastroenteropancreatic neuroendocrine neoplasms (WHO G3). Endocr Relat Cancer 2020;27:R67-R77.

108. Strosberg J, El-Haddad G, Wolin E, et al; NETTER-1 Trial Investigators. Phase 3 trial of ${ }^{177} \mathrm{Lu}$-dotatate for midgut neuroendocrine tumors. N Engl J Med 2017;376:125-135.

109. Brabander T, van der Zwan WA, Teunissen JJM, et al. Longterm efficacy, survival, and safety of $\left[{ }^{177} \mathrm{Lu}-\mathrm{DOTA}^{0}, \mathrm{Tyr}^{3}\right]$ octreotate in patients with gastroenteropancreatic and bronchial neuroendocrine tumors. Clin Cancer Res 2017;23:4617-4624.

110. Ezziddin S, Khalaf F, Vanezi M, et al. Outcome of peptide receptor radionuclide therapy with $177 \mathrm{Lu}$-octreotate in advanced grade $1 / 2$ pancreatic neuroendocrine tumours. Eur J Nucl Med Mol Imaging 2014;41:925-933.

111. Fross-Baron K, Garske-Roman U, Welin S, et al. 177LuDOTATATE therapy of advanced pancreatic neuroendocrine tumors heavily pretreated with chemotherapy; analysis of outcome, safety and their determinants. Neuroendocrinology 2020 Feb 25 [Online ahead of print]. doi: 10.1159/000506746

112. Bertani E, Fazio N, Radice D, et al. Resection of the primary tumor followed by peptide receptor radionuclide therapy as upfront strategy for the treatment of G1-G2 pancreatic neuroendocrine tumors with unresectable liver metastases. Ann Surg Oncol 2016;23:981-989.

113. Ezziddin S, Meyer C, Kahancova S, et al. 90Y Radioembolization after radiation exposure from peptide receptor radionuclide therapy. J Nucl Med 2012;53:1663-1669.

114. Braat AJAT, Ahmadzadehfar H, Kappadath SC, et al. Radioembolization with ${ }^{90} \mathrm{Y}$ resin microspheres of neuroendocrine liver metastases after initial peptide receptor radionuclide therapy. Cardiovasc Intervent Radiol 2020;43:246-253.

115. Braat AJAT, Bruijnen RCG, van Rooij R, et al. Additional holmium-166 radioembolisation after lutetium-177-dotatate in patients with neuroendocrine tumour liver metastases (HEPAR PLuS): a single-centre, single-arm, open-label, phase 2 study. Lancet Oncol 2020;21:561-570.

116. Kesavan M, Turner JH. Myelotoxicity of peptide receptor radionuclide therapy of neuroendocrine tumors: a decade of experience. Cancer Biother Radiopharm 2016;31:189-198.

117. Sonbol MB, Halfdanarson TR, Hilal T. Assessment of therapyrelated myeloid neoplasms in patients with neuroendocrine tumors after peptide receptor radionuclide therapy: a systematic review. JAMA Oncol 2020;6:1086-1092. 
Supplementary material

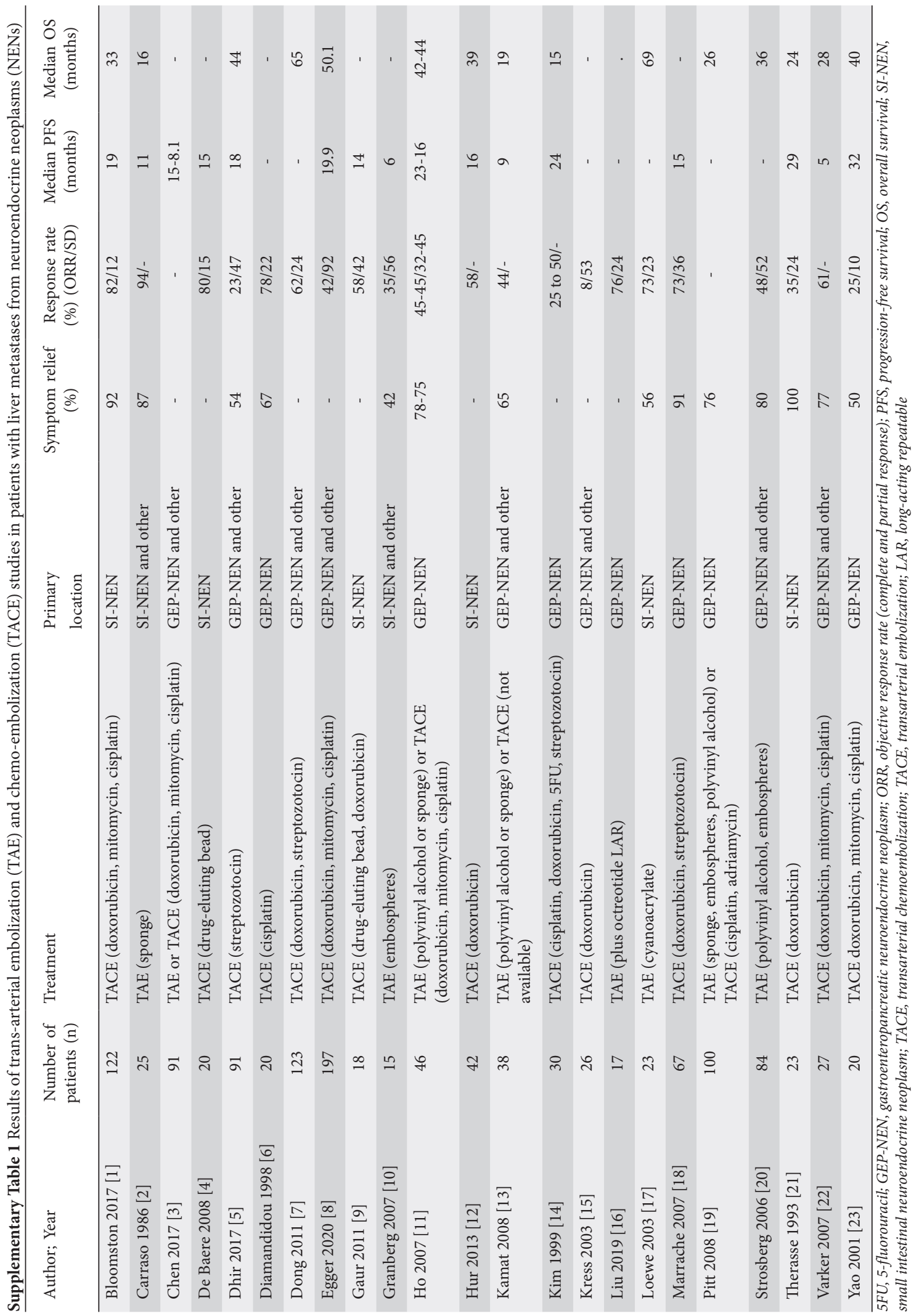




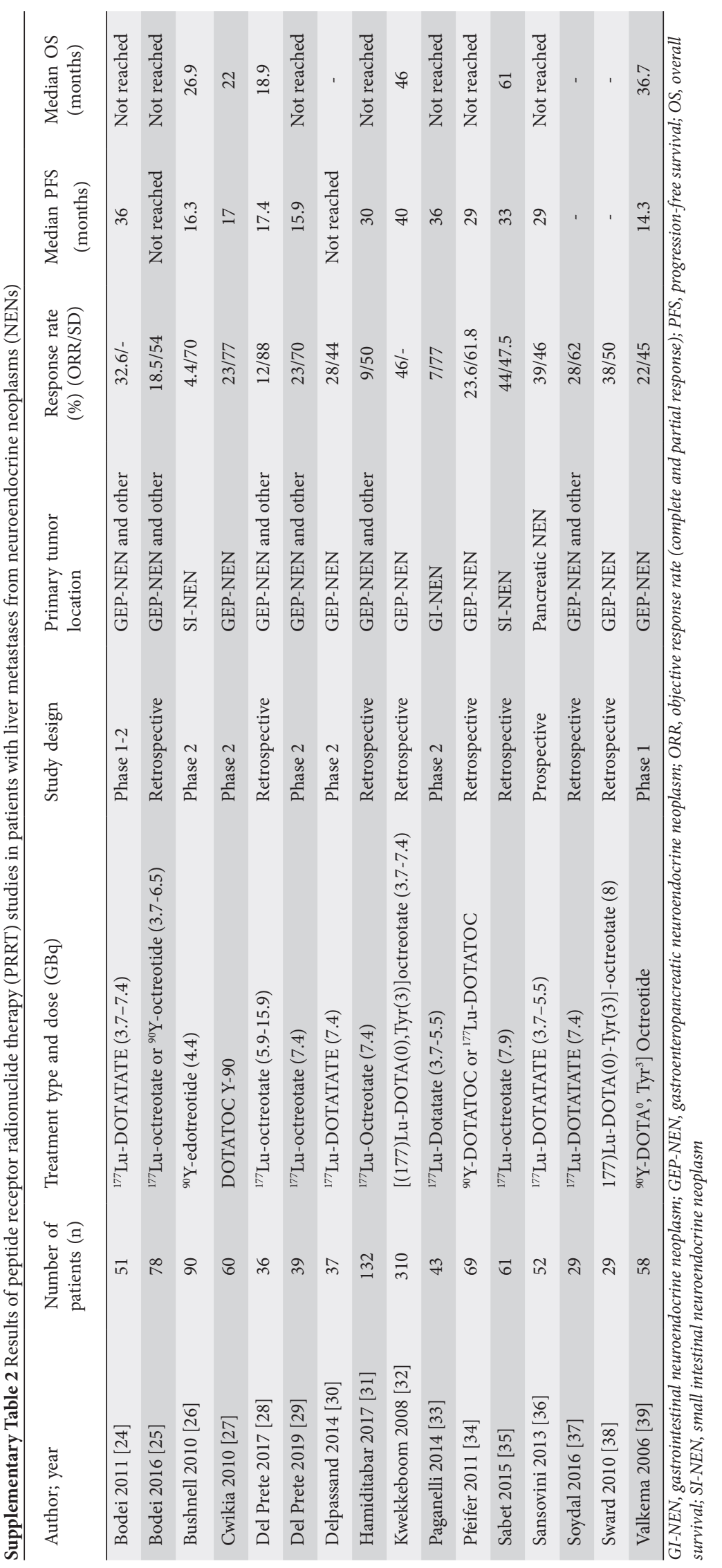




\section{Supplementary References}

1. Bloomston M, Al-Saif O, Klemanski D, et al. Hepatic artery chemoembolization in 122 patients with metastatic carcinoid tumor: lessons learned. J Gastrointest Surg 2007;11:264-271.

2. Carrasco CH, Charnsangavej C, Ajani J, Samaan NA, Richli W, Wallace $\mathrm{S}$. The carcinoid syndrome: palliation by hepatic artery embolization. AJR Am J Roentgenol 1986;147:149-154.

3. Chen JX, Rose S, White SB, et al. Embolotherapy for Neuroendocrine Tumor liver metastases: prognostic factors for hepatic progression-free survival and overall survival. Cardiovasc Intervent Radiol 2017;40:69-80.

4. de Baere T, Deschamps F, Teriitheau C, et al. Transarterial chemoembolization of liver metastases from well differentiated gastroenteropancreatic endocrine tumors with doxorubicin-eluting beads: preliminary results. J Vasc Interv Radiol 2008;19:855-861.

5. Dhir M, Shrestha R, Steel JL, Initial treatment of unresectable neuroendocrine tumor liver metastases with transarterial chemoembolization using streptozotocin: a 20 -year experience. Ann Surg Oncol 2017;24:450-459.

6. Diamandidou E, Ajani JA, Yang DJ, et al. Two-phase study of hepatic artery vascular occlusion with microencapsulated cisplatin in patients with liver metastases from neuroendocrine tumors. AJR Am J Roentgenol 1998;170:339-344.

7. Dong XD, Carr BI. Hepatic artery chemoembolization for the treatment of liver metastases from neuroendocrine tumors: a long-term follow-up in 123 patients. Med Oncol 2011;28(Suppl 1):S286-S290.

8. Egger ME, Armstrong E, Martin RC, et al. Transarterial chemoembolization vs radioembolization for neuroendocrine liver metastases: a multi-institutional analysis. J Am Coll Surg 2020;230:363-370.

9. Gaur SK, Friese JL, Sadow CA, et al. Hepatic arterial chemoembolization using drug-eluting beads in gastrointestinal neuroendocrine tumor metastatic to the liver. Cardiovasc Intervent Radiol 2011;34:566-572.

10. Granberg D, Eriksson LG, Welin S, et al. Liver embolization with trisacryl gelatin microspheres (embosphere) in patients with neuroendocrine tumors. Acta Radiol 2007;48:180-185.

11. Ho AS, Picus J, Darcy MD, et al. Long-term outcome after chemoembolization and embolization of hepatic metastatic lesions from neuroendocrine tumors. AJR Am J Roentgenol 2007;188:1201-1207.

12. Hur S, Chung JW, Kim HC, et al. Survival outcomes and prognostic factors of transcatheter arterial chemoembolization for hepatic neuroendocrine metastases. J Vasc Interv Radiol 2013;24:947-956; quiz 57.

13. Kamat PP, Gupta S, Ensor JE, et al. Hepatic arterial embolization and chemoembolization in the management of patients with large-volume liver metastases. Cardiovasc Intervent Radiol 2008;31:299-307.

14. Kim YH, Ajani JA, Carrasco CH, et al. Selective hepatic arterial chemoembolization for liver metastases in patients with carcinoid tumor or islet cell carcinoma. Cancer Invest 1999;17:474-478.

15. Kress O, Wagner HJ, Wied M, Klose KJ, Arnold R, Alfke H. Transarterial chemoembolization of advanced liver metastases of neuroendocrine tumors--a retrospective single-center analysis. Digestion 2003;68:94-101.

16. Liu YM, Lian F, Zhou XF, et al. Safety and efficacy of transarterial embolization combined with octreotide LAR on reducing tumor burden for neuroendocrine tumor liver metastasis. Zhonghua $Y i$ Xue Za Zhi 2019;99:1142-1146.

17. Loewe C, Schindl M, Cejna M, Niederle B, Lammer J, Thurnher S. Permanent transarterial embolization of neuroendocrine metastases of the liver using cyanoacrylate and lipiodol: assessment of mid- and long-term results. AJR Am J Roentgenol
2003;180:1379-1384.

18. Marrache F, Vullierme MP, Roy C, et al. Arterial phase enhancement and body mass index are predictors of response to chemoembolisation for liver metastases of endocrine tumours. $\mathrm{Br}$ J Cancer 2007;96:49-55.

19. Pitt SC, Knuth J, Keily JM, et al. Hepatic neuroendocrine metastases: chemo- or bland embolization? J Gastrointest Surg 2008;12:1951-1960

20. Strosberg JR, Choi J, Cantor AB, Kvols LK. Selective hepatic artery embolization for treatment of patients with metastatic carcinoid and pancreatic endocrine tumors. Cancer Control 2006;13:72-78.

21. Therasse E, Breittmayer F, Roche A, et al. Transcatheter chemoembolization of progressive carcinoid liver metastasis. Radiology. 1993;189:541-547.

22. Varker KA, Martin EW, Klemanski D, Palmer B, Shah MH, Bloomston M. Repeat transarterial chemoembolization (TACE) for progressive hepatic carcinoid metastases provides results similar to first TACE. J Gastrointest Surg 2007;11:1680-1685.

23. Yao KA, Talamonti MS, Nemcek A, et al. Indications and results of liver resection and hepatic chemoembolization for metastatic gastrointestinal neuroendocrine tumors. Surgery 2001;130:677682; discussion 82-85.

24. Bodei L, Cremonesi M, Grana CM, et al. Peptide receptor radionuclide therapy with (1)(7)(7)Lu-DOTATATE: the IEO phase I-II study. Eur J Nucl Med Mol Imaging 2011;38:2125-2135.

25. Bodei L, Kidd M, Modlin IM, et al. Measurement of circulating transcripts and gene cluster analysis predicts and defines therapeutic efficacy of peptide receptor radionuclide therapy (PRRT) in neuroendocrine tumors. Eur J Nucl Med Mol Imaging 2016;43:839-851.

26. Bushnell DL, Jr., O'Dorisio TM, O’Dorisio MS, et al. 90 Y-edotreotide for metastatic carcinoid refractory to octreotide. J Clin Oncol 2010;28:1652-1659.

27. Cwikla JB, Sankowski A, Seklecka N, et al. Efficacy of radionuclide treatment DOTATATE Y-90 in patients with progressive metastatic gastroenteropancreatic neuroendocrine carcinomas (GEP-NETs): a phase II study. Ann Oncol 2010;21:787-794.

28. Del Prete M, Buteau FA, Beauregard JM. Personalized (177) Lu-octreotate peptide receptor radionuclide therapy of neuroendocrine tumours: a simulation study. Eur J Nucl Med Mol Imaging 2017;44:1490-1500.

29. Del Prete M, Buteau FA, Arsenault F, et al. Personalized (177)Lu-octreotate peptide receptor radionuclide therapy of neuroendocrine tumours: initial results from the P-PRRT trial. Eur J Nucl Med Mol Imaging 2019;46:728-742.

30. Delpassand ES, Samarghandi A, Zamanian S, et al. Peptide receptor radionuclide therapy with 177Lu-DOTATATE for patients with somatostatin receptor-expressing neuroendocrine tumors: the first US phase 2 experience. Pancreas 2014;43:518-525.

31. Hamiditabar M, Ali M, Roys J, et al. Peptide receptor radionuclide therapy with $177 \mathrm{Lu}$-Octreotate in patients with somatostatin receptor expressing neuroendocrine tumors: six years' assessment. Clin Nucl Med 2017;42:436-443.

32. Kwekkeboom DJ, de Herder WW, Kam BL, et al. Treatment with the radiolabeled somatostatin analog $[177$ Lu-DOTA 0,Tyr3] octreotate: toxicity, efficacy, and survival. J Clin Oncol 2008;26:2124-2130.

33. Paganelli G, Sansovini M, Ambrosetti A, et al. 177 Lu-Dotaoctreotate radionuclide therapy of advanced gastrointestinal neuroendocrine tumors: results from a phase II study. Eur J Nucl Med Mol Imaging 2014;41:1845-1851.

34. Pfeifer AK, Gregersen T, Gronbaek H, et al. Peptide receptor radionuclide therapy with Y-DOTATOC and (177)Lu-DOTATOC in advanced neuroendocrine tumors: results from a Danish cohort treated in Switzerland. Neuroendocrinology 2011;93:189-196. 
35. Sabet A, Dautzenberg K, Haslerud T, et al. Specific efficacy of peptide receptor radionuclide therapy with (177)Lu-octreotate in advanced neuroendocrine tumours of the small intestine. Eur J Nucl Med Mol Imaging 2015;42:1238-1246.

36. Sansovini M, Severi S, Ambrosetti A, et al. Treatment with the radiolabelled somatostatin analog Lu-DOTATATE for advanced pancreatic neuroendocrine tumors. Neuroendocrinology 2013;97:347-354

37. Soydal C, Peker A, Ozkan E, Kucuk ON, Kir MK. The role of baseline Ga-68 DOTATATE positron emission tomography/ computed tomography in the prediction of response to fixed-dose peptide receptor radionuclide therapy with Lu-177 DOTATATE Turk J Med Sci 2016;46:409-413.

38. Sward C, Bernhardt P, Ahlman $\mathrm{H}$, et al. [177Lu-DOTA 0 -Tyr 3]-octreotate treatment in patients with disseminated gastroenteropancreatic neuroendocrine tumors: the value of measuring absorbed dose to the kidney. World J Surg 2010;34:1368-1372.

39. Valkema R, Pauwels S, Kvols LK, et al. Survival and response after peptide receptor radionuclide therapy with [90Y-DOTA0,Tyr3] octreotide in patients with advanced gastroenteropancreatic neuroendocrine tumors. Semin Nucl Med 2006;36:147-156. 